\title{
The Effect of the Support Structure and Size of Cu-based Oxygen Carriers on the Performance of Chemical Looping Air Separation
}

\author{
Hou-Chuan Wang*, Hsiu-Hsia Lee, Ming-Hui Chang, Hou-Peng Wan, Jui-Yen Cheng, \\ Ting-Yi Wu
}

Green Energy and Environment Research Laboratories, Industrial Technology Research Institute, Hsinchu 31040, Taiwan

\begin{abstract}
Chemical looping air separation (CLAS) is a novel and efficient method of producing high-purity oxygen because of its low-energy demands. Cu-based materials are suitable oxygen carriers (OCs) for CLAS. In the current study, Cu-based OCs in different particle sizes were prepared using various methods (viz., through mechanical mixing, impregnation, and coprecipitation) and different supporting materials (viz., $\mathrm{ZrO}_{2}, \mathrm{SiO}_{2}$, and $\mathrm{Al}_{2} \mathrm{O}_{3}$ ) and porosities (viz., in the mesopore range). This study evaluated the reactivity, reaction kinetics, and recyclability of these OCs by measuring their conversion rates for reduction (oxygen release) and oxidation (regeneration) in a thermogravimetric analyzer. $\mathrm{CuO} \mathrm{OCs}_{\mathrm{O}}$ on $\mathrm{ZrO}_{2}$ nanoparticles prepared through impregnation (CuZr-IM) exhibited almost complete conversion and the fastest reaction rates of all the OCs for reduction and oxidation. These characteristics are primarily attributable to the fine particles (100-250 nm) of the OCs. Furthermore, the $\mathrm{CuO}$ on the surface of the $\mathrm{ZrO}_{2}$ particles was distributed in a uniform pattern, as these fine particles displayed greater oxygen mobility and more rapid diffusion than the micrometer-sized particles paired with bulk materials. Kinetic analysis revealed that Avrami-Erofe'ev random nucleation and the subsequent growth reaction model with $n=2$ (A2), with an observed activation energy of $140.2 \mathrm{~kJ} \mathrm{~mol}^{-1}$ in our study, is the optimal fitting for CuZr-IM OC conversion during reduction, and a long-term-stability test indicated that this OC is an appropriate candidate for CLAS.
\end{abstract}

Keywords: Chemical looping; Oxygen carrier; Oxygen; $\mathrm{CuO} / \mathrm{ZrO}_{2}$; Kinetics mechanism.

\section{INTRODUCTION}

Oxy-fuel combustion is used for thermal power generation and as one of the carbon capture and storage technologies (Scheffknecht et al., 2011). Oxy-fuel combustion is the process of burning fuel using pure oxygen instead of air. It produces exhaust, which primarily comprises $\mathrm{CO}_{2}$ and $\mathrm{H}_{2} \mathrm{O}$. Almost pure $\mathrm{CO}_{2}$ can be obtained by condensing water vapor. In the oxy-fuel combustion process, the required oxygen is produced through air separation (Smith and Klosek, 2001). A cryogenic air separation (CAS) process is the most common and commercially available method for large-scale, highvolume $\left(>100 \mathrm{t} \mathrm{d}^{-1}\right)$, and high-purity $\mathrm{O}_{2}$ (99.5-99.8\%). However, the CAS method is complicated and highly energy-consuming because it involves the liquefaction of air and distillation of liquid air. The oxygen-specific power of the CAS process is $0.3-0.6(\mathrm{kWh}) \cdot\left(\mathrm{m}^{3} \mathrm{O}_{2}\right)^{-1}$ (Fan and $\mathrm{Zhu}$, 2015). Moreover, it may cause an explosion resulting from rough handling in the CAS process. The other methods of producing oxygen are pressure swing adsorption (PSA) and

\footnotetext{
${ }^{*}$ Corresponding author.

E-mail address: Erichcwang@itri.org.tw
}

membrane separation. The former method, which absorbs nitrogen by using adsorbent materials, such as zeolite or carbon molecular sieves, produced approximately $95 \%$ oxygen (Delavar and Nabian, 2015). PSA process is appropriate for small to medium volumes of $\mathrm{O}_{2}$ production $\left(10-100 \mathrm{t} \mathrm{d}^{-1}\right)$. The oxygen-specific power of the PSA was approximately $0.4(\mathrm{kWh}) \cdot\left(\mathrm{m}^{3} \mathrm{O}_{2}\right)^{-1}$. Membrane separation is another favorable technology for oxygen separation from air. Some advanced membranes, such as ion transport membranes (ITMs) for air separation, are currently available (Dyer et al., 2000). Oxygen ions are diffused through vacancies of ceramic membranes fabricated from metal oxides at high temperatures of $700-900^{\circ} \mathrm{C}$. The selectivity of $\mathrm{O}_{2}$ is approximately $100 \%$. Compared to CAS and PAS methods, ITMs are usually applied to small volumes of $\mathrm{O}_{2}$ production (approximately $20 \mathrm{t} \mathrm{d}^{-1}$ ) and generate extremely high-purity oxygen $(>99 \%)$. However, the inability to produce nitrogen and high cost of membrane materials are disadvantages of ITMs.

Chemical looping process (CLP) has been developed over the past few years (Fan, 2010; Chen et al., 20188; Chiu and $\mathrm{Ku}, 2012$ ). CLP is a novel oxy-fuel combustion technology in which metal oxide is used in place of air to offer oxygen for fuel combustion. Through a cyclic loop in between fuel and air reactors, the system can output heat for power generation with inherent $\mathrm{CO}_{2}$ capture without extra energy. 
Chemical looping with oxygen uncoupling (CLOU) is one operating mode of CLP (Mattisson et al., 2009; Imtiaz et al., 2013). The gas-phase oxygen produced by some specific metal oxides, such as $\mathrm{CuO}$ or $\mathrm{Mn}_{2} \mathrm{O}_{3}$, is directly reacted with solid fuels in order to produce nearly pure $\mathrm{CO}_{2}$ in the reducer. Chemical looping air separation (CLAS), which is another operating mode of CLP, is a novel alternative for oxygen production proposed by Moghtaderi (2010). In the CLAS process, oxygen carriers (OCs) containing metal oxides are circulated between an oxidation reactor (oxidizer) and a reduction reactor (reducer). In the reducer, OCs were reduced to produce gas-phase oxygen (Eq. (1)). In order to obtain higher-purity oxygen, steam or $\mathrm{CO}_{2}$ can be used as carrier gas in the reducer. The reduced OCs are then transported to an oxidizer. Fresh air is provided to the oxidizer to regenerate reduced OCs (Eq. (2)). CLAS is a cost-effective and energyefficient method to produce oxygen compared with CAS. The average oxygen-specific power of CLAS is approximately $0.04(\mathrm{kWh}) \cdot\left(\mathrm{m}^{3} \mathrm{O}_{2}\right)^{-1}$.

$$
\begin{aligned}
& \mathrm{Me}_{\mathrm{x}} \mathrm{O}_{\mathrm{y}} \leftrightarrow \mathrm{Me}_{\mathrm{x}} \mathrm{O}_{\mathrm{y}-2}+\mathrm{O}_{2(\mathrm{~g})} \\
& \mathrm{Me}_{\mathrm{x}} \mathrm{O}_{\mathrm{y}-2}+\mathrm{O}_{2(\mathrm{~g})} \leftrightarrow \mathrm{Me}_{\mathrm{x}} \mathrm{O}_{\mathrm{y}(\mathrm{g})}
\end{aligned}
$$

The selection of suitable OCs is the key issue in CLAS. In previous thermodynamic evaluation, some metal oxides, such as $\mathrm{Cu}-, \mathrm{Mn}-, \mathrm{Os}-$, and Co-based oxides, could release gas-phase oxygen at high temperatures (1100-1400 K) and were used as OCs for CLAS (Wang et al., 2013b). Among these metal oxides, $\mathrm{CuO}$ was the most suitable material for CLAS because of its higher oxygen transport capacity $\left(0.1\left(\mathrm{~g} \mathrm{O}_{2}\right) \cdot\left(\mathrm{g} \mathrm{CuO}^{-1}\right)\right.$ and higher reaction rates. However, the low melting point of $\mathrm{Cu}\left(1085^{\circ} \mathrm{C}\right)$ caused sintering and agglomeration, thus limiting its application at high temperature (Ku et al., 2017). Therefore, some inert materials, such as $\mathrm{Al}_{2} \mathrm{O}_{3}, \mathrm{SiO}_{2}, \mathrm{TiO}_{2}, \mathrm{ZrO}_{2}$, YSZ, and $\mathrm{MgAl}_{2} \mathrm{O}_{4}$, were used as supports for $\mathrm{Cu}$-based $\mathrm{OC}$ for increasing the reactivity, stability, mechanical strength, and sinter resistance. $\mathrm{SiO}_{2}$ is an appropriate support for $\mathrm{CuO}$ because $\mathrm{SiO}_{2}$ does not react with $\mathrm{CuO}$ at the oxygen-releasing temperature (Shah et al., 2012). However, agglomeration is the main problem of $\mathrm{SiO}_{2}$ support. Therefore, $\mathrm{CuO} / \mathrm{MgO}-\mathrm{SiO}_{2}$ OCs were synthesized (Song et al., 2014a). The results revealed that $\mathrm{MgO}$ addition on $\mathrm{SiO}_{2}$ support may suppress the agglomeration and increase the reactivity and stability during redox cycles due to the formations of $\mathrm{Cu}_{2} \mathrm{MgO}_{3}$ stabilizing the structure of OCs. Kinetics of $\mathrm{Cu}$-based OCs prepared with different support materials $\left(\mathrm{ZrO}_{2}, \mathrm{TiO}_{2}\right.$, and $\left.\mathrm{SiO}_{2}\right)$ for CLAS was studied by using thermogravimetry (TG) (Wang et al., 2013a). The results show that reaction rates of $\mathrm{Cu}$-based $\mathrm{OCs}$ with different supports were as follows: $\mathrm{ZrO}_{2}>\mathrm{TiO}_{2}>\mathrm{SiO}_{2}$. It may be attributed to the fact that a higher surface area of $\mathrm{ZrO}_{2}$ facilitates gas diffusion and heat transfer, thus increasing the reaction rate.

Different methods, such as mechanical mixing (MM), freeze granulation (FG), sol-gel (SG), impregnation (IM), coprecipitation $(\mathrm{CP})$, and spray drying (SD), were used to prepare $\mathrm{Cu}$-based OCs. $\mathrm{CuO} / \mathrm{Al}_{2} \mathrm{O}_{3}$ OCs with high $\mathrm{CuO}$ loadings were developed through a coprecipitation (CP) method (Imtiaz et al., 2012). It shows that the $\mathrm{pH}$ value influences the oxygen-carrying capacity and reactivity of OCs. $\mathrm{CuO} / \mathrm{Al}_{2} \mathrm{O}_{3}$ OCs synthesized at a high $\mathrm{pH}$ value (i.e., 12.5) resulted in OCs with a higher $\mathrm{CuO}$ content (87.8 wt.\%) and possessed a higher oxygen capacity. $\mathrm{CuO} / \mathrm{MgO}-\mathrm{SiO}_{2}$ OCs prepared using dry IM exhibit a higher stability than $\mathrm{CuO} / \mathrm{SiO}_{2}$ (Song et al., 2014a). The addition of $\mathrm{MgO}$ to $\mathrm{CuO} / \mathrm{SiO}_{2}$ and OCs prepared through IM method may suppress agglomeration.

Most studies on the preparation of $\mathrm{Cu}$-based OCs for CLAS have focused on the MM method because scaling up for the production of OCs is simpler and easier compared to the other methods. However, the particle size of most OCs has been on the micrometer scale (Wang et al., 2014; Ku et al., 2018). Some researches have been conducted on the effect of support microstructure and the particle size of OCs for CLAS. The relationship between the conversion rate and the open porosity of supports was also studied (Liu et al., 2016). It has been reported that the high open porosity of the support is beneficial for gas transfer, thus increasing the reaction rate. $\mathrm{CuO} / \mathrm{Al}_{2} \mathrm{O}_{3} \mathrm{OCs}$ derived from layered double hydroxide (LDH) precursors were prepared through $\mathrm{CP}$ method, and the OC was a two-dimensional (2D) nanostructured matrix (Song et al., 2013). It shows that the $\mathrm{CuO}$ nanocrystals (30$50 \mathrm{~nm}$ ) were well dispersed in porous LDH supports. The reaction rates were faster in both reduction and oxidation reaction because of $\mathrm{CuO}$ nanocomposites, and porous structures. Moreover, agglomeration was not observed for this nanostructured OC.

The objective of the current study is to prepare the Cu-based OCs for CLAS operation. Cu-based OCs with different support materials (e.g., $\mathrm{ZrO}_{2}, \mathrm{SiO}_{2}$, and $\mathrm{Al}_{2} \mathrm{O}_{3}$ ), pore structures, and particle sizes were prepared using various methods, such as IM, CP, and MM. The reactivity, kinetics, and recyclability of these $\mathrm{Cu}$-based OCs for CLAS reaction has been analyzed from the TGA results. It may lead to a better understanding of the correlation between the conversion rate and the particle size and porosity of supports.

\section{EXPERIMENTAL}

\section{Preparation of Oxygen Carrier}

In this study, Cu-based OCs with different structures and particle sizes were prepared using the following methods: IM, CP and MM. The content of $\mathrm{CuO}$ in the OCs is 40 wt. $\%$ in this study.

\section{Impregnation (IM)}

In this study, three $\mathrm{Cu}$-based OCs were prepared using $\mathrm{ZrO}_{2}, \mathrm{SiO}_{2}$, and $\mathrm{Al}_{2} \mathrm{O}_{3}$ as support materials. $\mathrm{ZrO}_{2}$ support was prepared through modified sol-gel methods (Mokhtar et al., 2013). Zr precursors were prepared using an aqueous solution of $\mathrm{ZrOCl}_{2}-8 \mathrm{H}_{2} \mathrm{O}$ (Solution A). Ammonia solution $(28 \%)$ was mixed with cetyltrimethylammonium bromide and homogeneously stirred for $30 \mathrm{~min}$ (Solution B). Solution B was added dropwise into Solution A and the mixture was stirred in an ultrasonic bath for $2 \mathrm{~h}$. $\mathrm{NaOH}$ was then slowly added to the solution until $\mathrm{pH}$ reached 9.0. The formed precipitate was transferred to an autoclave and heated 
at $85^{\circ} \mathrm{C}$ for $24 \mathrm{~h}$. The precipitate was filtered and repeatedly washed using ethanol. The resulting sample was dried in an oven at $100^{\circ} \mathrm{C}$ for $4 \mathrm{~h}$ and calcined at $600^{\circ} \mathrm{C}$ for $6 \mathrm{~h}$.

Mesoporous $\mathrm{SiO}_{2}$ support was synthesized using the spray-drying (SD) method (Wang et al., 2012). Sodium silicate was added to deionized water and $6 \mathrm{~N} \mathrm{HCl}$. The mixture was stirred at room temperature for 30 min until a clean solution was obtained. In a separate beaker, Pluronic P123 was added to EtOH (95\%) and thoroughly mixed. The Pluronic P123/EtOH solution was added to the sodium silicate mixture to obtain a precursor solution. The precursor was dried in a pilot-scale SD system. The drying temperature of a reaction tower for solvent removal from self-organized particles was $200^{\circ} \mathrm{C}$. The resulting $\mathrm{SiO}_{2}$ particles were collected using a cyclone and bag filter. The collected particles were finally calcined $\left(600^{\circ} \mathrm{C}\right.$, $4 \mathrm{~h}$ ) in a muffle furnace to eliminate the surfactant template.

Mesoporous $\mathrm{Al}_{2} \mathrm{O}_{3}$ support was prepared through a modified sol-gel method. In a general synthesis, Pluronic P123 and anhydrous ethanol were mixed for $30 \mathrm{~min}$ (Solution A). Aluminum isopropoxide, $\mathrm{HNO}_{3}$ solution, and anhydrous ethanol were mixed for $1 \mathrm{~h}$ (Solution B). Solution A was added dropwise into Solution B and the mixture was stirred for $1 \mathrm{~h}$. The mixed sample was aged for $20 \mathrm{~h}$ at room temperature. The resulting sample was dried in an oven at $100^{\circ} \mathrm{C}$ for $4 \mathrm{~h}$ and calcined at $600^{\circ} \mathrm{C}$ for $6 \mathrm{~h}$.

Three types of homogeneous $\mathrm{Cu}$-based OCs were prepared through IM using $\mathrm{ZrO}_{2}, \mathrm{SiO}_{2}$, and $\mathrm{Al}_{2} \mathrm{O}_{3}$ as supports and $\mathrm{Cu}\left(\mathrm{NO}_{3}\right)_{2}-3 \mathrm{H}_{2} \mathrm{O}$ as the copper precursor. In the IM procedure, the copper precursor solution was dissolved in deionized water and slowly added in the aforementioned support materials. The solution was then stirred for $1 \mathrm{~h}$. The resulting sample was dried in an oven at $100^{\circ} \mathrm{C}$ for $12 \mathrm{~h}$ and calcined at $900^{\circ} \mathrm{C}$ for $3 \mathrm{~h}$.

\section{Coprecipitation $(C P)$}

The OC was prepared through $\mathrm{CP}$ using $\mathrm{Cu}\left(\mathrm{NO}_{3}\right)_{2}-3 \mathrm{H}_{2} \mathrm{O}$ and $\mathrm{ZrOCl}_{2}-8 \mathrm{H}_{2} \mathrm{O}$ as materials. $\mathrm{Cu}\left(\mathrm{NO}_{3}\right)_{2}-3 \mathrm{H}_{2} \mathrm{O}$ and $\mathrm{ZrOCl}_{2}-8 \mathrm{H}_{2} \mathrm{O}$ were added in water and stirred for $1 \mathrm{~h}$. Aqueous $\mathrm{NaOH}$ was gradually added until $\mathrm{pH}$ reached 9.0 and precipitation occurred. The resulting sample was dried in an oven at $80^{\circ} \mathrm{C}$ overnight and calcined at $900^{\circ} \mathrm{C}$.

\section{Mechanical Mixing (MM)}

OCs were prepared through $\mathrm{MM}$ using commercial $\mathrm{CuO}$ as an active material for releasing $\mathrm{O}_{2}$ and $\mathrm{ZrO}_{2}$ powders as support materials ( $\mathrm{Ku}$ et al., 2018). The particle sizes of these metal oxide materials were $1-10 \mu \mathrm{m}$. $\mathrm{CuO}$ powder was mixed with water and support materials, and $10 \mathrm{wt} . \%$ binder was added and mixed. OC samples were dried at $80^{\circ} \mathrm{C}$ for $12 \mathrm{~h}$ and calcined at $900^{\circ} \mathrm{C}$ for $3 \mathrm{~h}$.

The resulting OCs were denoted as $C u S-P$, where letters $S$ and $P$ represent support materials, such as $\mathrm{ZrO}_{2}(\mathrm{Zr}), \mathrm{SiO}_{2}$ ( $\mathrm{Si})$, and $\mathrm{Al}_{2} \mathrm{O}_{3}(\mathrm{Al})$, and the preparation method of the $\mathrm{OC}$, such as MM, IM, and CP. For example, OCs was prepared through $\mathrm{IM}$ and $\mathrm{ZrO}_{2}$ as support, the resulting $\mathrm{Cu}$-based OCs were termed $\mathrm{CuZr-IM}$ OCs.

\section{Oxygen Carrier Characterization}

The physical properties of the OCs were determined by
$\mathrm{N}_{2}$ adsorption/desorption at $77 \mathrm{~K}$ via a Micromeritics ASAP 2020 volumetric sorption analyzer (Norcross, GA). Before measurement, OCs were degassed under high vacuum at $100^{\circ} \mathrm{C}$ for $3 \mathrm{~h}$ until water vapor and impurities on the surface of the OCs have been desorbed. $\mathrm{N}_{2}$ adsorption/desorption isotherms were measured at a relative pressure $\left(\mathrm{P}_{\mathrm{N} 2} / \mathrm{P}_{0}\right)$ range of 0.0001-0.99 and employed to determine surface area, pore volume, and average pore diameter via the Barrett-JohnerHalenda (BJH) equation for pore size of 1.7-100 $\mathrm{nm}$. The particle size and surface morphologies of the OCs were characterized via a field emission scanning electron microscope (SEM, JEOL JSM-6500F/CL (Gatan MonoCL3 plus HSPMT)) and a high-resolution transmission electron microscopy, energy-dispersive X-ray spectroscopy (TEM, JEM-2100F/EDS (Oxford X-MAX $80 \mathrm{~mm}^{2}$ )). The crystal phase of the OCs was characterized by a powder X-ray diffractometer (XRD, Mac Science Co., Ltd., Japan) using $\mathrm{Cu} \mathrm{K}$ radiation $(40 \mathrm{kV}, 30 \mathrm{~mA})$. The actual $\mathrm{CuO}$ content was analyzed via an inductively coupled plasma-optical emission spectrometer (ICP-OES, Agilent 5100).

\section{Reactivity Test}

Conversion of $O C S$

Reactivity tests of the oxygen carriers were carried out in a thermogravimetric analyzer (TGA, SETSYS Evolution 24, SETARAM). The temperature of TGA chamber was elevated with a ramping rate of $10^{\circ} \mathrm{C} \mathrm{min}^{-1}$ from room temperature to $900^{\circ} \mathrm{C}$. The carry gas used for oxygen release in the reducer was pure $\mathrm{N}_{2}$, and the gas used for the regeneration of OCs in the oxidizer was air. Previous study (Song et al., 2014b) indicated that no obvious difference was observed in the reactivity of oxygen carriers with different inert reducing environments $\left(\mathrm{N}_{2}\right.$ or $\left.\mathrm{CO}_{2}\right)$. Therefore, $\mathrm{N}_{2}$ was usually used as the regeneration gas. The flow rate of the reacting gas was

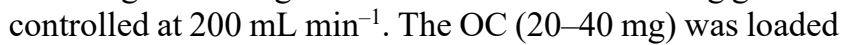
in a platinum basket and heated to $900^{\circ} \mathrm{C}$. The duration was set at $60 \mathrm{~min}$ for reduction and oxidation. The data of weight changes can be used for the conversion of OCs using the following equations:

$$
\begin{aligned}
& X_{r}(\%)=\frac{m_{o}-m(t)}{m_{o}-m_{r}} \times 100 \% \\
& X_{o}(\%)=\frac{m(t)-m_{r}}{m_{o}-m_{r}} \times 100 \%
\end{aligned}
$$

where $X_{r}$ and $X_{o}$ are the conversions of OCs during reduction and oxidation, respectively; and $m_{o}, m(t)$, and $m_{r}$ are the masses of the sample in a completely oxidized state, during the test, and in a completely reduced state, respectively.

In addition to conversion, the oxygen transport capacity (OTC) and reaction rate of solid conversion (ROC) could be determined (Song et al., 2014b). The OTC and ROC of OCs were defined as follows:

$\operatorname{OTC}\left(\mathrm{g} \mathrm{O}_{2} \mathrm{~g}^{-1}\right)=\frac{m_{o}-m_{r}}{m_{o}}$ 
$\operatorname{ROC}\left(\% \min ^{-1}\right)=\frac{d X}{d t}$

\section{Reaction Kinetics in Reduction}

The reduction kinetics of $\mathrm{Cu}$-based OCs for CLAS were calculated using the procedure reported by the previous study (Song et al., 2014c; Wang et al., 2016). In this study, the reaction rate for reduction of $\mathrm{Cu}$-based OCs was evaluated using the following equations:

$$
\frac{d X}{d t}\left(\% \min ^{-1}\right)=k f(X)\left(C-C_{e q}\right)^{n}
$$

where $X, f(X)$, and $t$ are the conversion of OCs during reduction, kinetic mechanism functions, and reaction times, respectively; $C$ and $C_{e q}$ are oxygen concentrations used for oxidation and equilibrium oxygen concentration used for $\mathrm{CuO}$ decomposition, respectively; $n$ and $k$ are the reaction order and reaction rate constant following the Arrhenius equation; and:

$$
k\left(\min ^{-1}\right)=A \exp \left(-\frac{E_{a}}{R T}\right)
$$

where $A, E_{a}, R$, and $T$ represent the pre-exponential factor, activation energy, gas constant, and reaction temperature, respectively.

The value of $n$ is zero because the reduction of $\mathrm{CuO}$ is a thermal decomposition process and oxygen is not present in the reactive gas $\left(\mathrm{N}_{2}\right.$ as the carrier gas). Therefore, Eq. (7) can be simplified as follows:

$\frac{d X}{d t}\left(\% \min ^{-1}\right)=k f(X)$

The integral form of Eq. (9) is as follows:

$G(X)=k t$

where $G(X)$ is a kinetic mechanism function, which can be obtained from different gas-solid reaction mechanisms. Table 1 summarizes $G(X)$ equations for different reaction mechanisms (Song et al., 2014c). For example, $G(X)$ under the $\mathrm{D} 1$ reaction mechanism is determined by the value of $X^{2}$. Therefore, the reaction rate constant $(k)$ can be calculated using the slope of the fitting line in the plots of $G(X)$ of $X^{2}$ versus reaction time.

\section{RESULTS AND DISCUSSION}

\section{Characterization of $\mathrm{OCS}$}

The OCs comprising 40 wt.\% $\mathrm{CuO}$ on various support materials $\left(\mathrm{ZrO}_{2}, \mathrm{SiO}_{2}, \mathrm{Al}_{2} \mathrm{O}_{3}\right)$ were prepared in this study. Table 2 lists the oxygen transport capacity, BET surface area, and pore volume of the OCs. For CuZr-IM OC, the precursor solution of copper was impregnated on the surface of $\mathrm{ZrO}_{2}$ particles. The particle size and BET surface area of $\mathrm{ZrO}_{2}$ supports were $15-25 \mathrm{~nm}$ and $37.8 \mathrm{~m}^{2} \mathrm{~g}^{-1}$, respectively. After IM, the size of CuZr-IM OCs was 100-250 nm. Therefore, CuZr-IM OCs can be classified as fine particles. Fig. 1 shows SEM images of OCs in general. The fresh OCs had a BET surface area and pore volume of $1.43 \mathrm{~m}^{2} \mathrm{~g}^{-1}$ and $16.8 \mathrm{~mm}^{3} \mathrm{~g}^{-1}$, respectively. A crystalline phase from the XRD analysis shows $\mathrm{CuO}$ and $\mathrm{ZrO}_{2}$.

For $\mathrm{CuZr}-\mathrm{CP}$, the $\mathrm{OC}$ was prepared through $\mathrm{CP}$. It reported that $\mathrm{pH}$ affects the reactivity and crushing strength of OCs (Imtiaz et al., 2012). In this study, the $\mathrm{pH}$ of 9.0 was selected because the OCs had high reactivity and mechanical strength. The particle size of the CuZr-CP was $20-50 \mu \mathrm{m}$, which is larger than that of CuZr-IM OC. The fresh OCs had a BET surface area and pore volume of $1.20 \mathrm{~m}^{2} \mathrm{~g}^{-1}$ and $11.3 \mathrm{~mm}^{3} \mathrm{~g}^{-1}$, respectively. The crystalline phase showed $\mathrm{CuO}$ and $\mathrm{ZrO}_{2}$ in XRD analysis.

For CuSi-IM, the precursor solution of copper was impregnated into the mesoporous $\mathrm{SiO}_{2}$ particle. The particle size of the $\mathrm{SiO}_{2}$ support was $1-10 \mu \mathrm{m}$. The average BET surface area and pore size of $\mathrm{SiO}_{2}$ were approximately $250 \mathrm{~m}^{2} \mathrm{~g}^{-1}$ and 3-6 nm, respectively. After the IM of copper nitrate, the particle size of CuSi-IM OCs was 3-10 $\mu \mathrm{m}$. The fresh CuSi-IM OCs had a BET surface area of $6.05 \mathrm{~m}^{2} \mathrm{~g}^{-1}$ and a pore volume of $35.0 \mathrm{~mm}^{3} \mathrm{~g}^{-1}$, which were larger than

Table 1. $G(X)$ equations for different reaction mechanisms.

\begin{tabular}{ll}
\hline Reaction mechanism model & $G(X)$ equation \\
\hline One-dimensional diffusion (D1) & $X^{2}$ \\
Two-dimensional diffusion (D2) & $(1-X) \ln (1-X)+X$ \\
Three-dimensional diffusion, Jandar function (D3) & {$\left[1-(1-X)^{1 / 3}\right]^{2}$} \\
Three-dimensional diffusion, G-B function (D4) & $1-2 X / 3-(1-X)^{2 / 3}$ \\
First-order chemical reaction (C1) & $-\ln (1-X)$ \\
Second-order chemical reaction (C2) & $(1-X)^{-1}-1$ \\
Avrami-Erofe'ev random nucleation and subsequent growth reaction model with $n=2(\mathrm{~A} 2)$ & {$[-\ln (1-X)]^{1 / 2}$} \\
Avrami-Erofe'ev random nucleation and subsequent growth reaction model with $n=3$ (A3) & {$[-\ln (1-X)]^{1 / 3}$} \\
Phase boundary reaction with $n=2$ (R2) & $1-(1-X)^{1 / 2}$ \\
Phase boundary reaction with $n=3$ (R3) & $1-(1-X)^{1 / 3}$ \\
Mampel power law with $n=1$ (P1) & $X$ \\
Mampel power law with $n=2$ (P2) & $X^{1 / 2}$ \\
Mampel power law with $n=3$ (P3) & $X^{1 / 3}$ \\
Mampel power law with $n=4(\mathrm{P} 4)$ & $X^{1 / 4}$ \\
\hline
\end{tabular}


Table 2. Properties of Cu-based OCs.

\begin{tabular}{llllll}
\hline Oxygen carrier & $\begin{array}{l}\text { Theoretical } \mathrm{CuO} \\
\text { loading }(\%)\end{array}$ & $\begin{array}{l}\text { Actual } \mathrm{CuO} \\
\text { Loading }(\%)\end{array}$ & $\begin{array}{l}\text { Oxygen transport } \\
\text { capacity }\left(\mathrm{g}-\mathrm{O}_{2} \mathrm{~g}^{-1}\right)\end{array}$ & $\begin{array}{l}\text { BET surface } \\
\text { area }\left(\mathrm{m}^{2} \mathrm{~g}^{-1}\right)\end{array}$ & $\begin{array}{l}\text { BJH pore } \\
\text { volume }\left(\mathrm{mm}^{3} \mathrm{~g}^{-1}\right)\end{array}$ \\
\hline $\mathrm{CuZr-MM}$ & 40.0 & 41.5 & 0.42 & 1.36 & 5.16 \\
$\mathrm{CuZr-IM}$ & 40.0 & 39.9 & 0.40 & 1.43 & 16.8 \\
$\mathrm{CuZr-CP}$ & 40.0 & 38.2 & 0.38 & 1.20 & 14.1 \\
$\mathrm{CuSi}-\mathrm{IM}$ & 40.0 & 38.8 & 0.39 & 6.05 & 35.1 \\
\hline
\end{tabular}
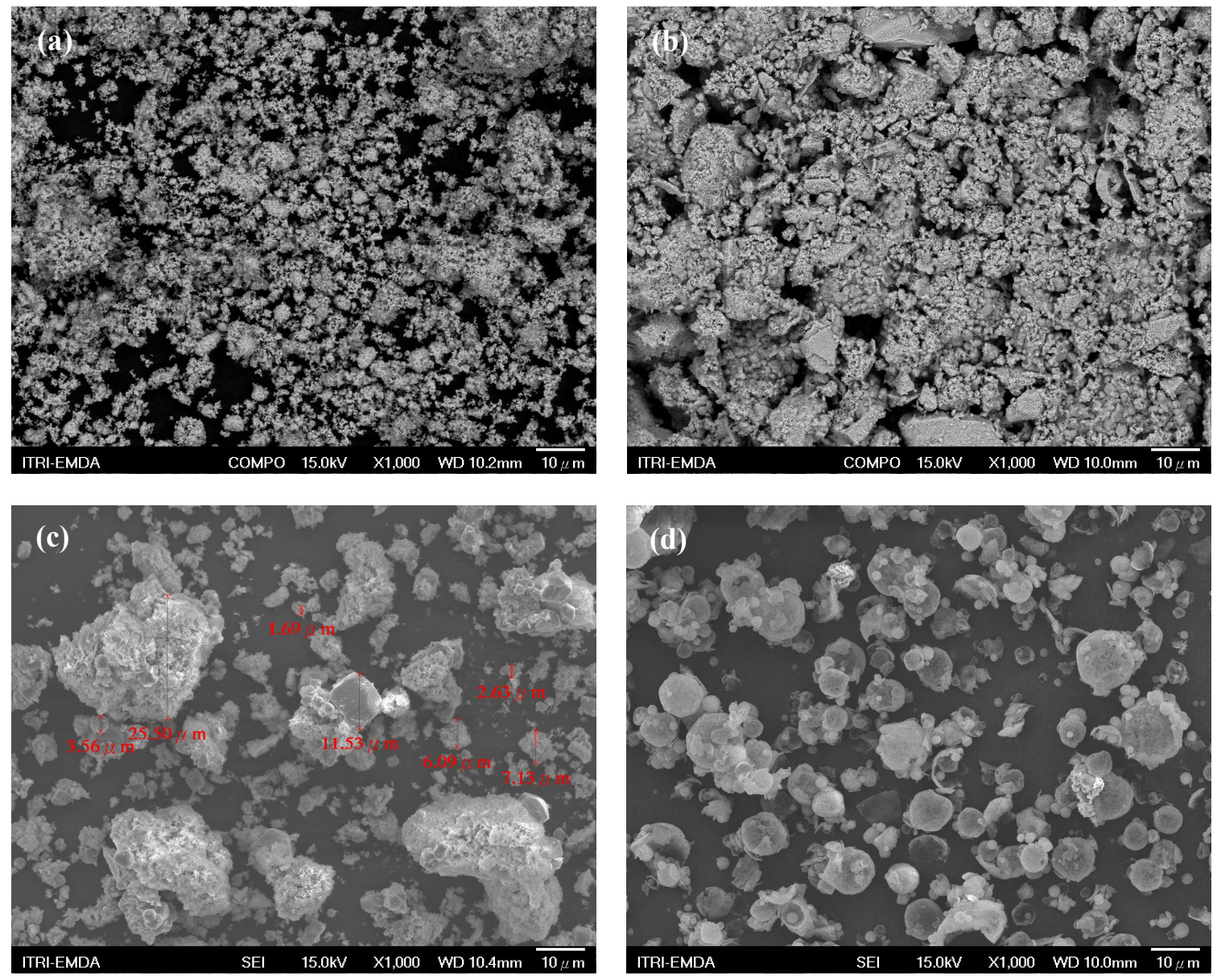

Fig. 1. SEM images of (a) CuZr-MM, (b) CuZr-IM, (c) CuZr-CP, and (d) CuSi-IM OCs.

those of CuZr-IM and CuZr-CP. The crystalline phase showed $\mathrm{CuO}$ and $\mathrm{SiO}_{2}$ in the XRD analysis.

\section{Reactivity of OCs}

\section{Effect of Support Material}

In this study, three materials (i.e., $\mathrm{ZrO}_{2}, \mathrm{SiO}_{2}$, and $\mathrm{Al}_{2} \mathrm{O}_{3}$ ) with different particle sizes and pore structures were used as a support for $\mathrm{Cu}$-based OCs. All Cu-based OCs were prepared through IM because OCs have high reactivity and satisfactory mechanical strength (de Diego et al., 2004). Fig. 2 presents the effect of the support material on the reactivity of Cu-based OCs for CLAS. The reaction temperature of reduction and oxidation was controlled at $900^{\circ} \mathrm{C}$. CuZr-IM exhibited superior conversion and faster reaction rate during reduction. This result may be attributed to the particle size of the $\mathrm{ZrO}_{2}$ support. The $\mathrm{ZrO}_{2}$ supports used for $\mathrm{CuZr}$-IM were prepared through a modified sol-gel method. $\mathrm{ZrO}_{2}$ supports were nanoparticles with a particle size of $15-25 \mathrm{~nm}$ (Fig. 3). After the IM of nano-sized $\mathrm{ZrO}_{2}$, the particle size of CuZr-IM OC was $100-250 \mathrm{~nm}$, which is considerably smaller than that of other OCs. Fig. 4 shows TEM images and the corresponding EDX mapping of CuZr-IM; a high degree of dispersion of $\mathrm{CuO}$ was observed on the surface of $\mathrm{ZrO}_{2}$ supports. The oxygen mobility, diffusion, and heat transfer of fine particles were superior to those of bulk materials with micrometer-sized particles, thus facilitating OC reactivity. These findings are consistent with those of a previous study (Song et al., 2013).

For the $\mathrm{CuSi}$-IM OC, the mesoporous $\mathrm{SiO}_{2}$ support was prepared through SD. The particle size of the prepared $\mathrm{SiO}_{2}$ was $1.0-10.0 \mu \mathrm{m}$. The pore size and BET surface area of the $\mathrm{SiO}_{2}$ support were 3-6 nm and approximately $250 \mathrm{~m}^{2} \mathrm{~g}^{-1}$, respectively. After IM of the copper precursor, the particle size of CuSi-IM was 3-15 $\mu \mathrm{m}$. Although the BET surface 

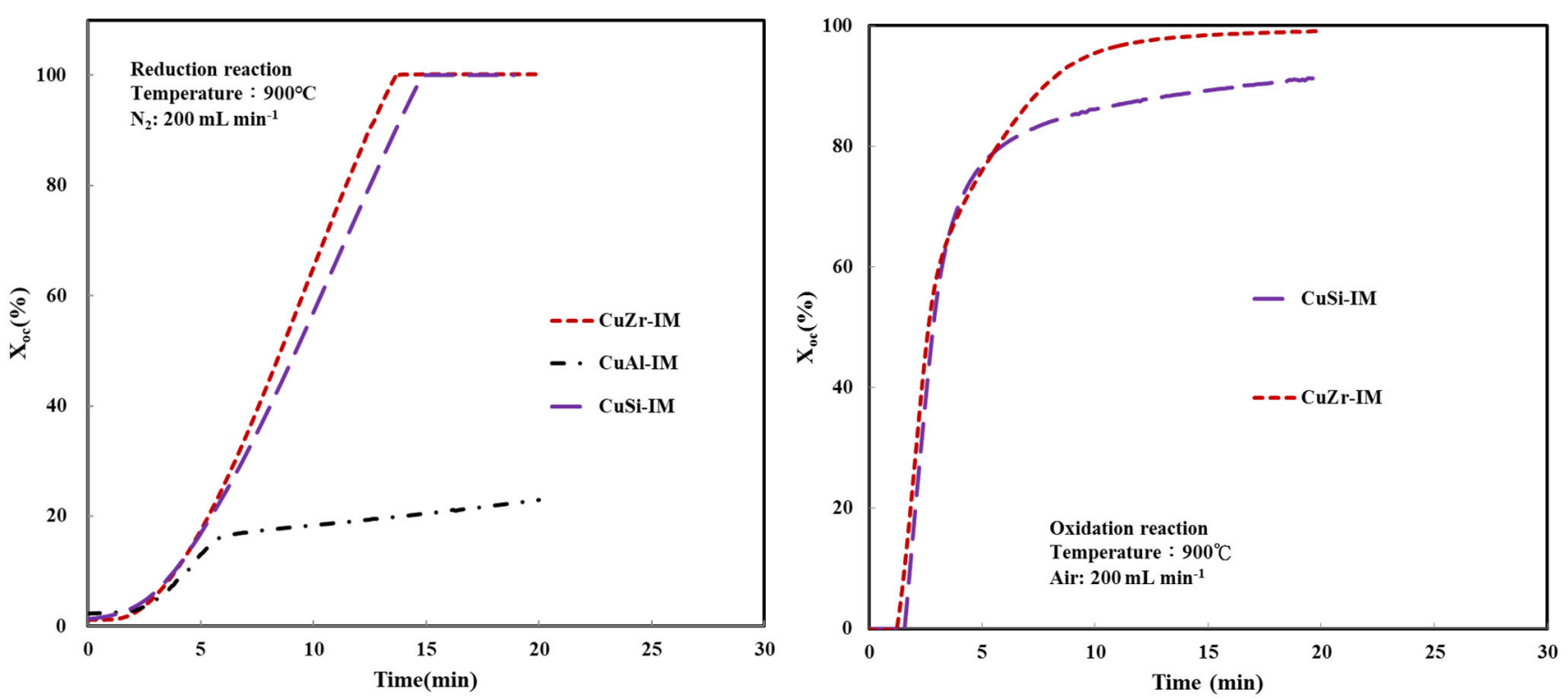

Fig. 2. Effect of support material on the conversion of $\mathrm{Cu}$-based OCs in reduction and oxidation.
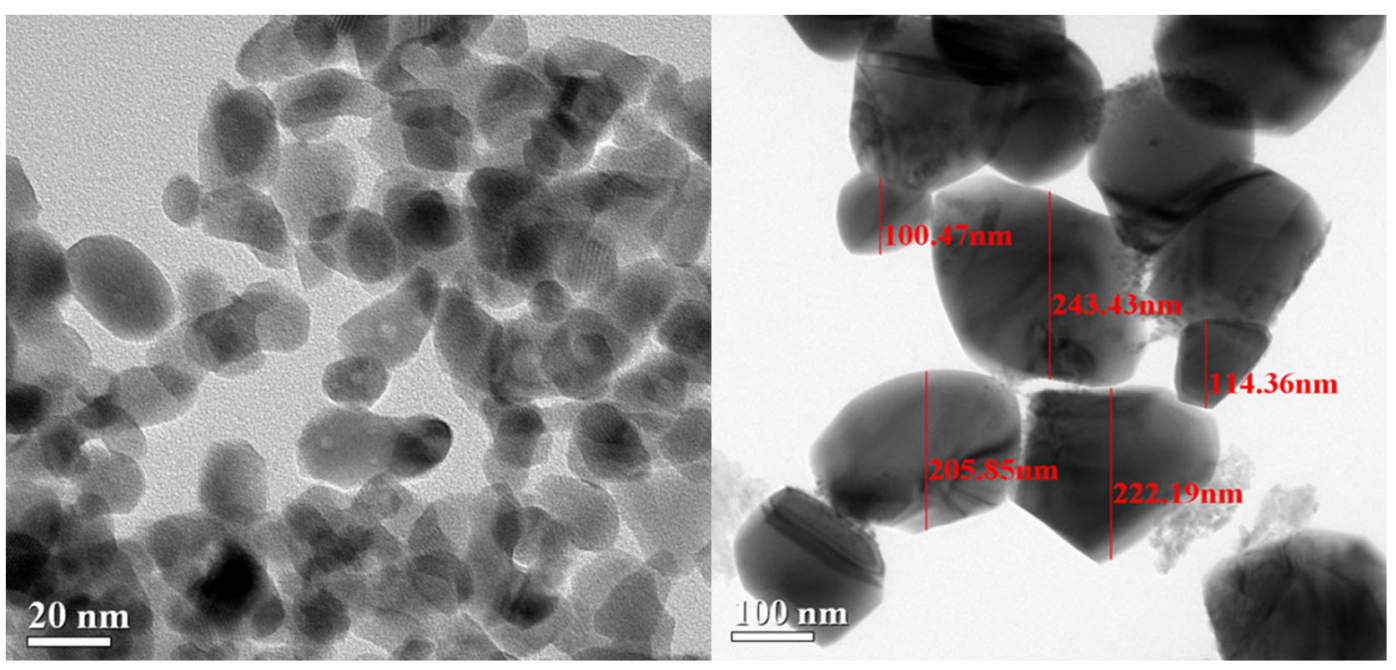

Fig. 3. TEM images of $\mathrm{ZrO}_{2}$ support (left) and $\mathrm{CuZr-IM} \mathrm{OCs} \mathrm{(right).}$

area of porous $\mathrm{SiO}_{2}$ support was $250 \mathrm{~m}^{2} \mathrm{~g}^{-1}$. However, $\mathrm{CuO}$ will impregnate into the porous $\mathrm{SiO}_{2}$ and then full up the pores due to high loading (40 wt.\%). Moreover, the OC will be calcined at high temperature of $900^{\circ} \mathrm{C}$. The surface area of CuSi-IM OC was therefore decreased dramatically.

Fig. 5 shows TEM images of mesoporous $\mathrm{SiO}_{2}$ support and $\mathrm{CuSi}$-IM OCs; the particle size of $\mathrm{CuO}$ on the surface of the $\mathrm{SiO}_{2}$ support ranged from 6-13 nm. The TEM images indicate a fine dispersion of copper oxide on the $\mathrm{SiO}_{2}$ support (Fig. 6). The porosity of the $\mathrm{SiO}_{2}$ support and $\mathrm{CuO}$ nanoparticles may enhance reactivity performance and provide high conversion and a fast reaction rate during reduction. However, the particle size of CuSi-IM OCs was 3$15 \mu \mathrm{m}$. The reactivity of $\mathrm{CuSi}$-IM was slightly less than that of CuZr-IM. Moreover, the regeneration of CuSi-IM OC was incomplete during oxidation because of the slight agglomeration of CuSi-IM OCs during redox (Fig. 7).

The $\mathrm{CuO}$ supported on the mesoporous $\mathrm{Al}_{2} \mathrm{O}_{3}$ support
(CuAl-IM OC) showed lower conversion (approximately $25 \%$ ) during the reduction process compared with $\mathrm{CuZr-IM}$ and $\mathrm{CuSi}$-IM. This result can be attributed to the formation of copper aluminate $\left(\mathrm{CuAl}_{2} \mathrm{O}_{4}\right)$ between the $\mathrm{CuO}$ and $\mathrm{Al}_{2} \mathrm{O}_{3}$ support during calcination (Eq. (11)), which significantly reduced the oxygen release of the OC. Fig. 8 shows XRD patterns of $\mathrm{CuAl}-\mathrm{IM}$, indicating that copper aluminate $\left(\mathrm{CuAl}_{2} \mathrm{O}_{4}\right)$ was present. This finding is in accordance with the results of previous studies (Abad et al., 2012; Song et al., 2014a). $\mathrm{CuAl}_{2} \mathrm{O}_{4}$ is a very stable substance with a reduction temperature of about $900-1000^{\circ} \mathrm{C} . \mathrm{CuAl}_{2} \mathrm{O}_{4}$ will decomposed slowly to form $\mathrm{Al}_{2} \mathrm{O}_{3}$ and $\mathrm{O}_{2}$ in the anoxic environment (reduction reaction, Eq. (12)), but also $\mathrm{CuAlO}_{2}$ is formed at the same time, so $\mathrm{CuAl}_{2} \mathrm{O}_{4}$ can only be partially regenerated into $\mathrm{CuO}$. Therefore, the amount of $\mathrm{CuO}$ capable of releasing oxygen reduced, which means $\mathrm{Al}_{2} \mathrm{O}_{3}$ is not a suitable support material for the oxygen-releasing carrier despite having a mesoporous structure. The aforementioned analysis indicates 

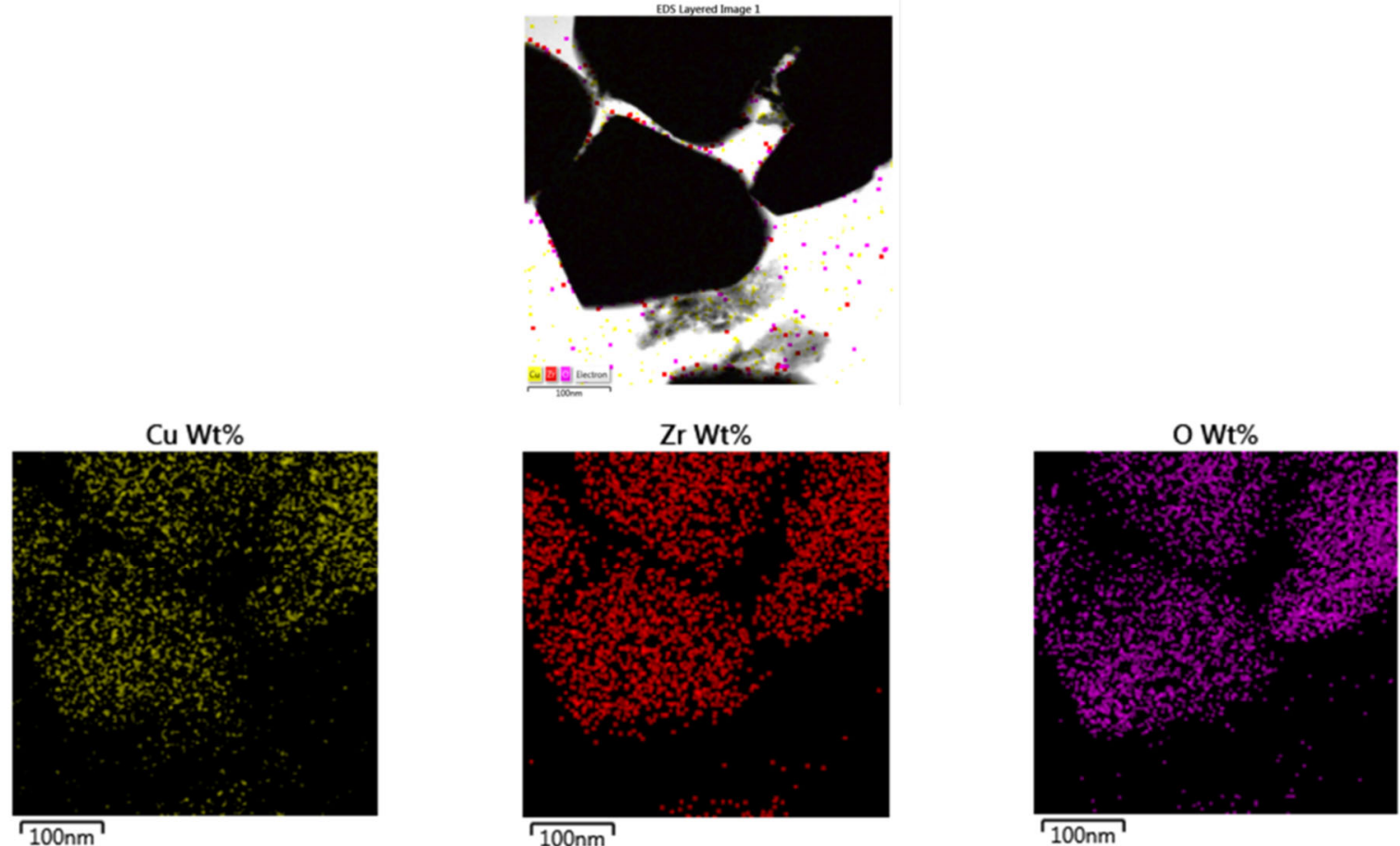

Fig. 4. TEM images and corresponding EDX mapping of CuZr-IM OCs.

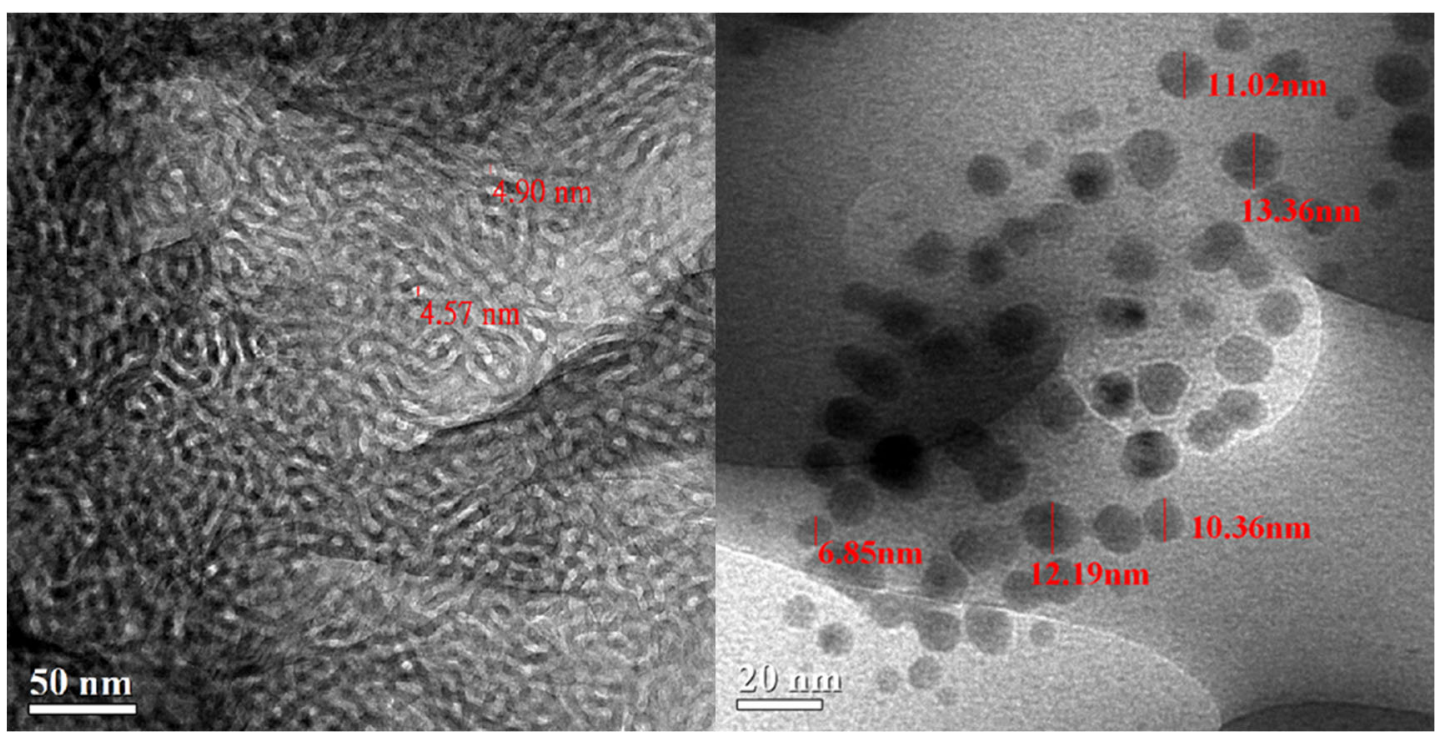

Fig. 5. TEM images of mesoporous $\mathrm{SiO}_{2}$ support (left) and CuSi-IM OCs (right).

that nanosized $\mathrm{ZrO}_{2}$ may be a good choice as the support material of OC.

$\mathrm{CuO}+\mathrm{Al}_{2} \mathrm{O}_{3} \rightarrow \mathrm{CuAl}_{2} \mathrm{O}_{4}$

$4 \mathrm{CuAl}_{2} \mathrm{O}_{4} \rightarrow 4 \mathrm{CuAlO}_{2}+2 \mathrm{Al}_{2} \mathrm{O}_{3}+\mathrm{O}_{2}$

\section{Effect of Preparation Method of the OC}

Fig. 9 shows the conversions of three 40 wt.\% Cu-based OCs using $\mathrm{ZrO}_{2}$ as supports obtained through various preparation methods in one reduction and oxidation (redox) cycle in CLAS. The reaction temperature of redox was controlled at $900^{\circ} \mathrm{C}$. OCs prepared through IM were more reactive than those prepared through $\mathrm{CP}$ and $\mathrm{MM}$. CuZr-IM OC had a high conversion rate of nearly $100 \%$. Furthermore, the average ROC was the fastest in the reduction process $\left(7.40 \% \mathrm{~min}^{-1}\right.$ ) (Table 3 ). This result may be attributed to the particle size of the OCs. The aforementioned analysis indicates high conversion of $\mathrm{CuZr}-\mathrm{IM}$ results from the $\mathrm{CuO}$ homogeneously dispersed on the nanosized $\mathrm{ZrO}_{2}$ supports. Although CuZr-CP OCs have higher crushing strength, the particle size was larger than that of CuZr-IM. The particle size determines reactivity performance, including conversion and reaction rate, in CLAS. 

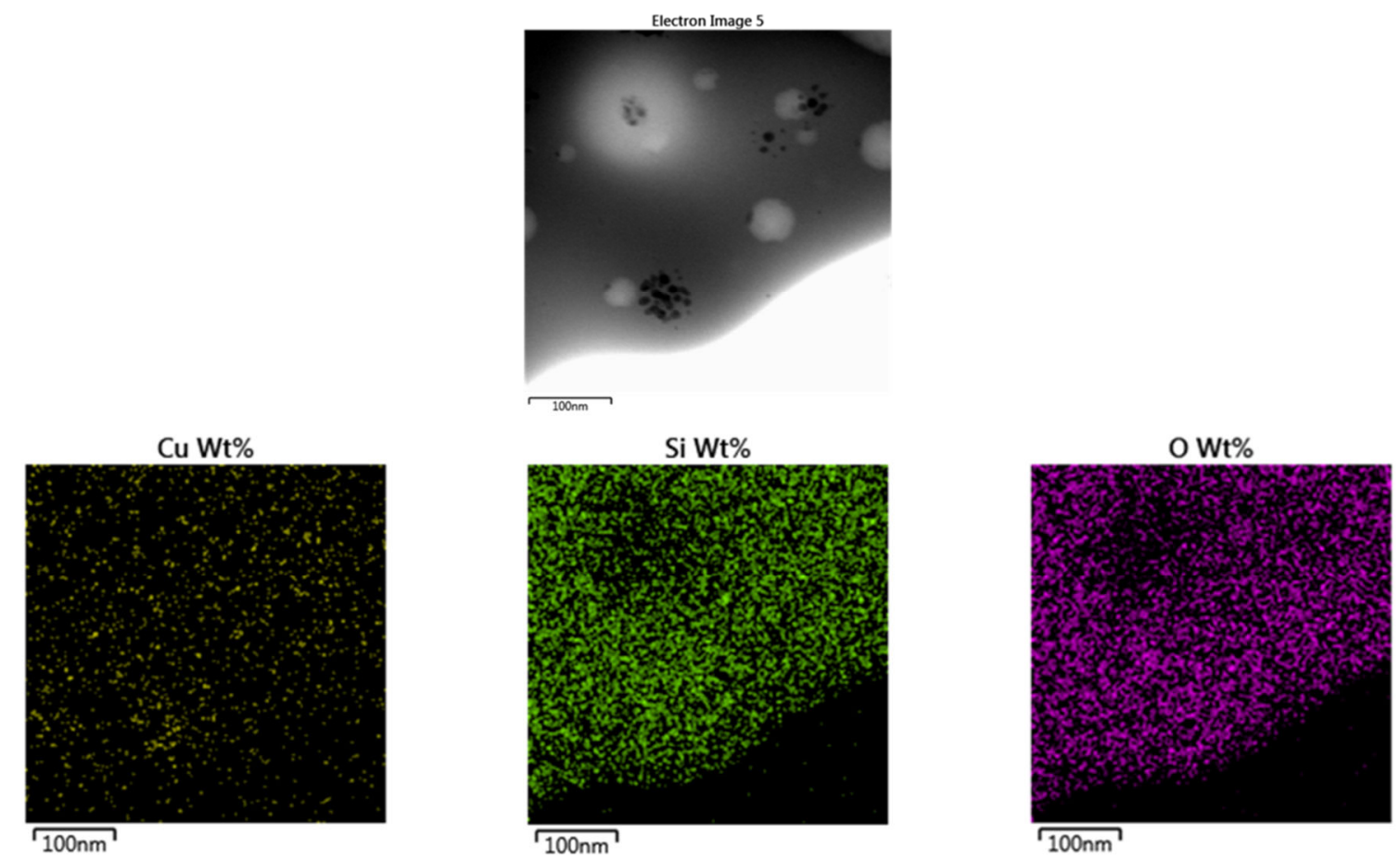

Fig. 6. TEM images and corresponding EDX mapping of CuSi-IM OCs.

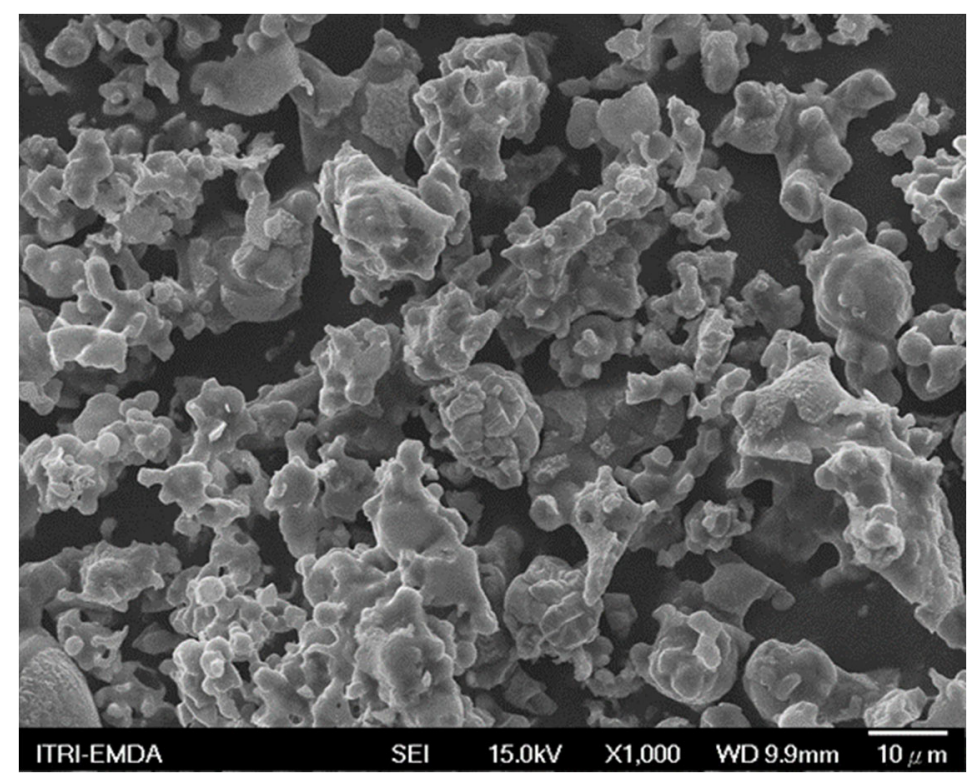

Fig. 7. SEM images of used CuSi-IM OCs after redox reaction.

For the regeneration of reduced OCs during oxidation in air at a temperature of $825-950^{\circ} \mathrm{C}$, the average rates of solid conversion were $16.58 \%, 11.57 \%$, and $5.78 \% \mathrm{~min}^{-1}$ for $\mathrm{CuZr-IM}$, CuZr-CP, and CuZr-MM, respectively. CuZr-IM $\mathrm{OC}$ exhibited the fastest kinetics. Moreover, this result may be attributed to the particle size of OCs. Furthermore, the oxidation rate of the OC was considerably faster than the reduction rate. These results are consistent with previous study (Song et al., 2014c). CuZr-IM OCs exhibited the highest conversion and fastest reaction rate during redox in CLAS.

\section{Kinetic Analysis of OCs during Reduction}

As stated previously, $\mathrm{CuZr}$-IM was the most suitable $\mathrm{Cu}$ based OC for CLAS because of its high conversion and reaction rate during redox. Therefore, $\mathrm{CuZr}$-IM was selected as an $\mathrm{OC}$ for the determination of chemical kinetics during reduction in CLAS.

Table 1 summarizes $G(X)$ equations of different gas-solid reaction mechanisms. The reaction rate constant $(k)$ can be calculated from the slope of the fitting line in a plot of $G(X)$ versus time. Table 4 presents the results of $R^{2}$ values for fitting different reaction mechanisms based on $\mathrm{CuZr}$-IM 


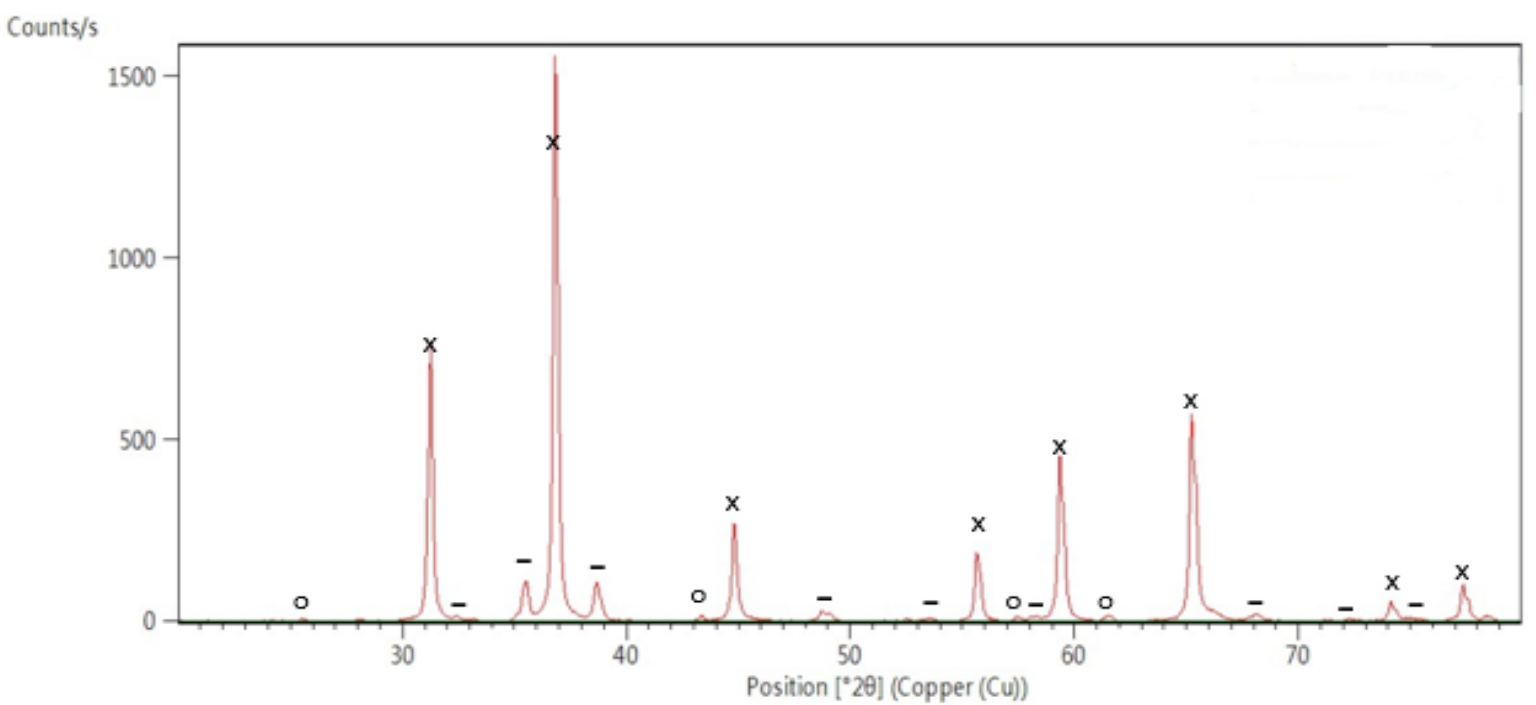

Fig. 8. XRD patterns of CuAl-IM OCs. The major reflection peaks are annotated as: $\mathrm{CuO}(-), \mathrm{Al}_{2} \mathrm{O}_{3}(\mathrm{o}), \mathrm{CuAl}_{2} \mathrm{O}_{4}(\mathrm{x})$.
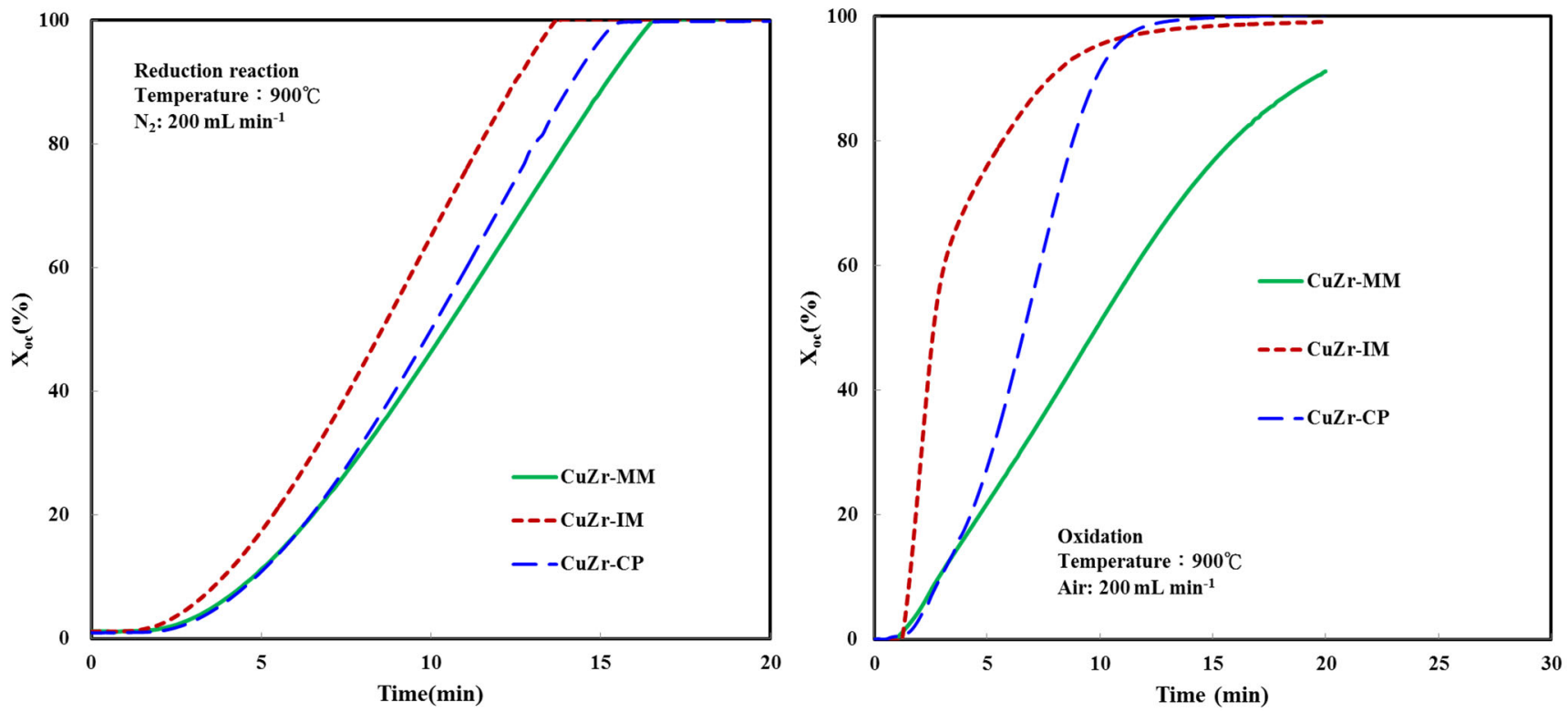

Fig. 9. Conversion of $\mathrm{Cu}$-based OCs during reduction and oxidation reaction for CLAS.

Table 3. Rates of conversion for $\mathrm{Cu}$-based OCs during reduction and oxidation.

\begin{tabular}{lll}
\hline Cu-based oxygen carrier & $\begin{array}{l}\text { Rate of conversion (ROC) in reduction } \\
\left(\% \mathrm{~min}^{-1}\right)\end{array}$ & $\begin{array}{l}\text { Rate of conversion (ROC) in oxidation } \\
\left(\% \mathrm{~min}^{-1}\right)\end{array}$ \\
\hline $\mathrm{CuZr-IM}$ & 7.40 & 16.58 \\
$\mathrm{CuZr-CP}$ & 5.35 & 11.57 \\
$\mathrm{CuZr-MM}$ & 5.14 & 5.78 \\
$\mathrm{CuSi}-\mathrm{IM}$ & 7.17 & 16.30 \\
\hline
\end{tabular}

OCs during reduction at a temperature of $825-950^{\circ} \mathrm{C}$. It indicated that Avrami-Erofe'ev random nucleation and the subsequent growth reaction model with $n=2$ (A2) are the optimal fit for $\mathrm{CuO}$-based $\mathrm{OC}$ conversion during reduction in CLAS. Therefore, the oxygen release of OCs was determined using the rates of nucleation, nuclei growth, and nucleus formation.
The kinetic mechanism function $G(X)$ under the $\mathrm{A} 2$ reaction model is determined by the value of $[-\ln (1-X)]^{1 / 2}$. Fig. 10 shows the results of the fitting curves of $G(X)$ versus reaction time at different reduction temperatures. Table 5 presents linear correlation coefficient $\left(R^{2}\right)$ values of the least-squares linear fitting and rate constants for temperatures from 825 to $950^{\circ} \mathrm{C}$. Rate constants were $0.0636,0.0831,0.1271,0.1820,0.23$, and 
Table 4. $R^{2}$ for fitting different reaction mechanisms based on CuZr-IM conversion during reduction.

\begin{tabular}{lllllllllllllll}
\hline $\begin{array}{l}\mathrm{T} \\
\left({ }^{\circ} \mathrm{C}\right)\end{array}$ & $\mathrm{D} 1$ & $\mathrm{D} 2$ & $\mathrm{D} 3$ & $\mathrm{D} 4$ & $\mathrm{C} 1$ & $\mathrm{C} 2$ & $\mathrm{~A} 2-1$ & $\mathrm{~A} 2-2$ & $\mathrm{~A} 3$ & $\mathrm{R} 2$ & $\mathrm{R} 3$ & $\mathrm{P} 1$ & $\mathrm{P} 2$ & $\mathrm{P} 3$ \\
\hline 825 & 0.6789 & 0.6592 & 0.6384 & 0.6523 & 0.7534 & 0.8294 & 0.9929 & 0.992 & 0.6912 & 0.8998 & 0.8297 & 0.9194 & 0.882 & 0.2543 \\
850 & 0.6746 & 0.6405 & 0.6023 & 0.6276 & 0.7567 & 0.7348 & 0.9964 & 0.9848 & 0.8407 & 0.8735 & 0.8604 & 0.9084 & 0.9543 & 0.5695 \\
875 & 0.6989 & 0.6592 & 0.614 & 0.6439 & 0.8021 & 0.7287 & 0.9933 & 0.9896 & 0.7663 & 0.8930 & 0.878 & 0.9319 & 0.9233 & 0.4151 \\
900 & 0.7182 & 0.6605 & 0.5884 & 0.6363 & 0.845 & 0.6007 & 0.9894 & 0.9954 & 0.8535 & 0.8818 & 0.8576 & 0.9386 & 0.9408 & 0.5117 \\
925 & 0.725 & 0.6581 & 0.5659 & 0.6274 & 0.8322 & 0.4862 & 0.9764 & 0.9965 & 0.934 & 0.8269 & 0.8316 & 0.9311 & 0.966 & 0.6566 \\
950 & 0.7345 & 0.6825 & 0.5929 & 0.653 & 0.878 & 0.4845 & 0.9647 & 0.9990 & 0.9817 & 0.8571 & 0.8272 & 0.9190 & 0.9778 & 0.7919 \\
\hline
\end{tabular}

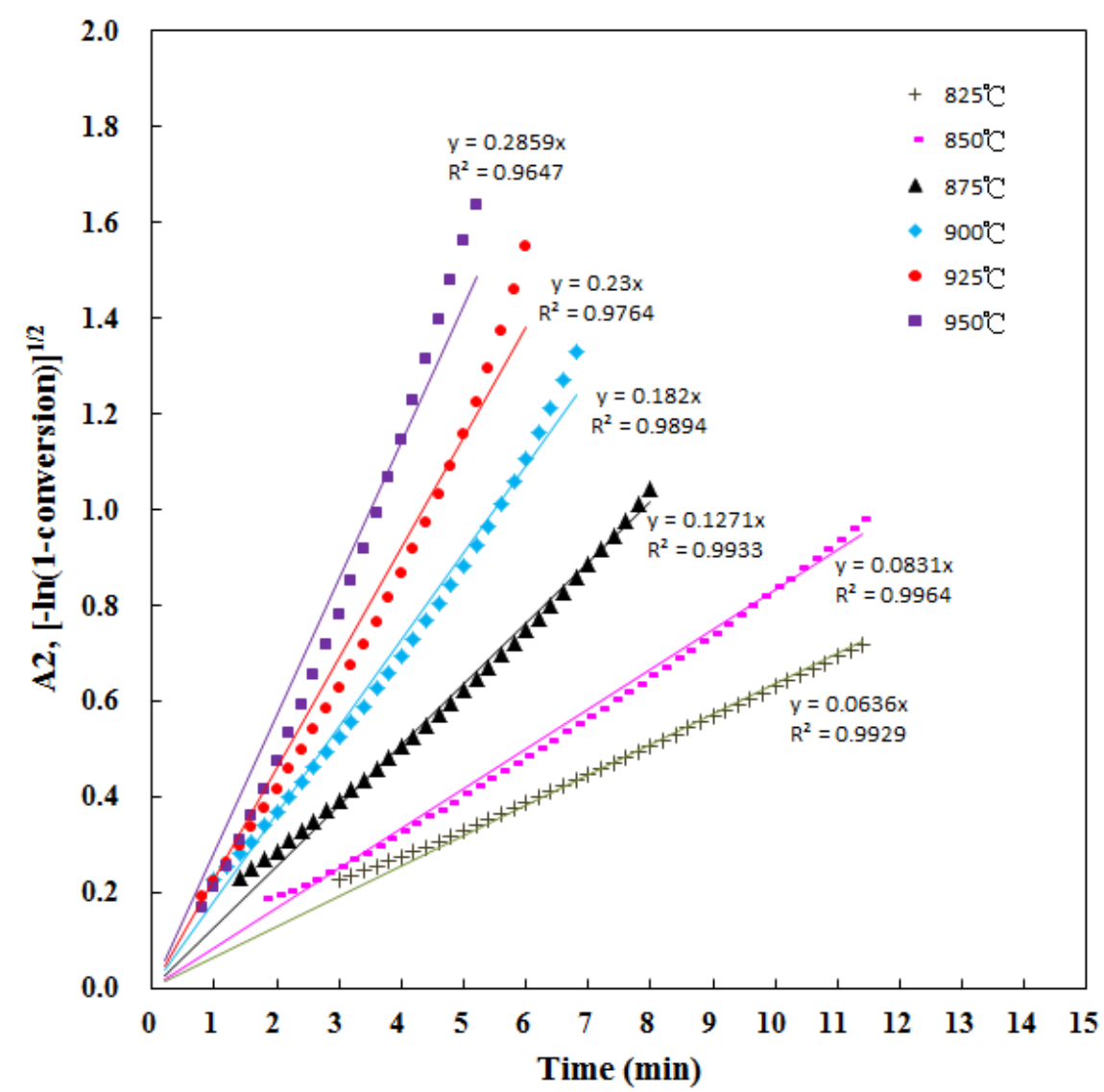

Fig. 10. Plots of $G(X)$ versus reaction time of CuZr-IM at different temperatures during reduction.

Table 5. Fitting results of OC conversion during reduction at different temperatures.

\begin{tabular}{lll}
\hline Reaction temperature $\left({ }^{\circ} \mathrm{C}\right)$ & $R^{2}$ values for fitting linear & The reaction rate constant $(k)$ \\
\hline 825 & 0.9929 & 0.0636 \\
850 & 0.9964 & 0.0831 \\
875 & 0.9933 & 0.1271 \\
900 & 0.9894 & 0.1820 \\
925 & 0.9764 & 0.230 \\
950 & 0.9647 & 0.2859 \\
\hline
\end{tabular}

0.2859 for $825,850,875,900,925$, and $950^{\circ} \mathrm{C}$, respectively. The rate constant increased with the reduction temperature, indicating that high temperature is advantageous for thermal decomposition and oxygen release of CuZr-IM OCs.

The activation energy can be calculated according to the Arrhenius equation. Fig. 11 shows the fitting lines of $\ln (k)$ versus $1000 / T$ for the reduction of CuZr-IM OCs. The values of activation energy $\left(E_{a}\right)$ and pre-exponential factor $(A)$ can be obtained by calculating the slope and intercept of the fitting line. The $E_{a}$ of $140.2 \mathrm{~kJ} \mathrm{~mol}^{-1}$ and $A$ of $2.82 \times 10^{5} \mathrm{~min}^{-1}$ at a temperature of $825-950^{\circ} \mathrm{C}$ were lower than those of micrometer-sized $\mathrm{CuO} / \mathrm{SiO}_{2}$ OCs $\left(176 \mathrm{~kJ} \mathrm{~mol}^{-1}\right)$ at temperatures higher than $900^{\circ} \mathrm{C}$ (Song et al., 2014c). CuZrIM OC with lower activation energy may be attributed to the 


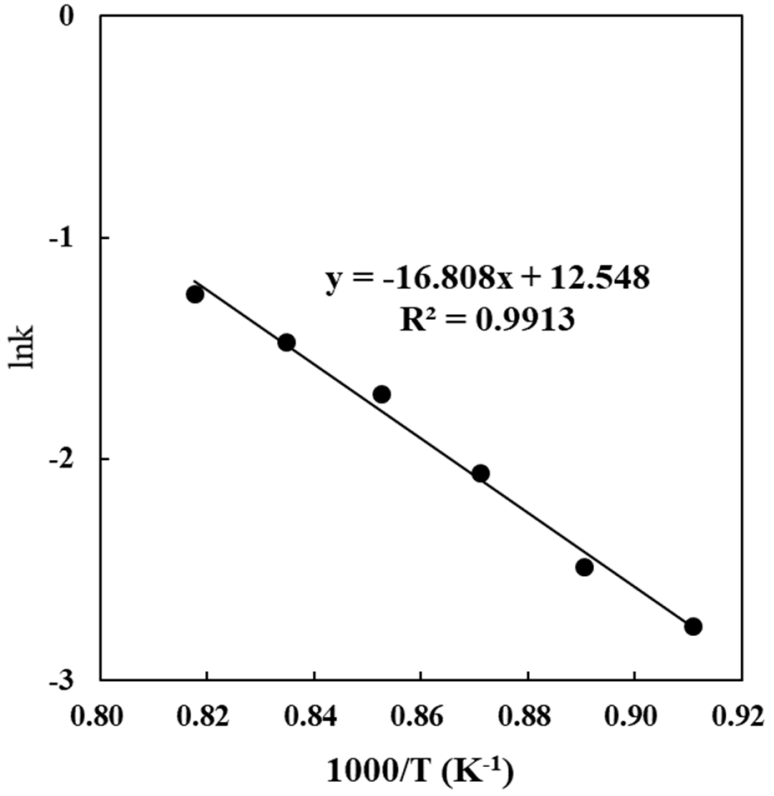

Fig. 11. Plots of $\ln (k)$ versus $1000 / T$ of CuZr-IM OCs at different temperatures during reduction.

decreasing particle size (Alalwan et al., 2018). This result is consistent with that of a previous study (Pang et al., 2009).

The conversion of CuZr-IM OCs during reduction can be obtained using kinetic parameters according to Eq. (10). Fig. 12 shows the prediction results, which indicated that the predicted value (line) was close to the experimental values (dot points) at reaction temperatures of $825-950^{\circ} \mathrm{C}$.
Stability of $O C s$

Based on the aforementioned analysis, CuZr-IM OCs are better for CLAS. In addition to a high conversion and fast reaction rate, long-term recyclability and durability are necessary for OCs. These can reduce the fine-particle purging, thereby reducing the fresh OC makeup rate. To determine the long-term reaction stability, a 20-cycle redox test was performed on CuZr-IM OCs at $900^{\circ} \mathrm{C}$ using a TGA. The OTC of an OC is defined as the difference in the mass fraction between the completely oxidized and reduced forms. This can be a critical index to determine the favorability for oxygen transport (Song et al., 2014b). Fig. 13 shows the weight fraction of $\mathrm{CuZr-IM}$ OCs during 20 consecutive redox cycles, indicating CuZr-IM OCs with a stable OTC in CLAS. The reduced OCs were completely reoxidized during oxidation. Furthermore, the CuZr-IM was converted over 20 redox cycles. The CuZr-IM OCs maintained relatively stable conversion. Comparison of the fresh and used OCs after 20 redox cycles in CLAS revealed no evident agglomeration for the used OCs (Fig. 14).

\section{CONCLUSION}

In this study, the reactivity and conversion rates of novel $\mathrm{Cu}$-based OCs prepared with various methods and different supporting materials for CLAS were studied. Cu-based OCs impregnated with supporting $\mathrm{ZrO}_{2}$ nanoparticles $(\mathrm{CuZr}-\mathrm{IM}$ OCs) exhibited excellent performance and can be employed in CLAS to produce oxygen at temperatures of $825-950^{\circ} \mathrm{C}$. This result can be attributed to the small particle size of the OCs. The $\mathrm{CuO}$ nanoparticles on the surface of the nano- $\mathrm{ZrO}_{2}$ supports were distributed in a uniform pattern and displayed

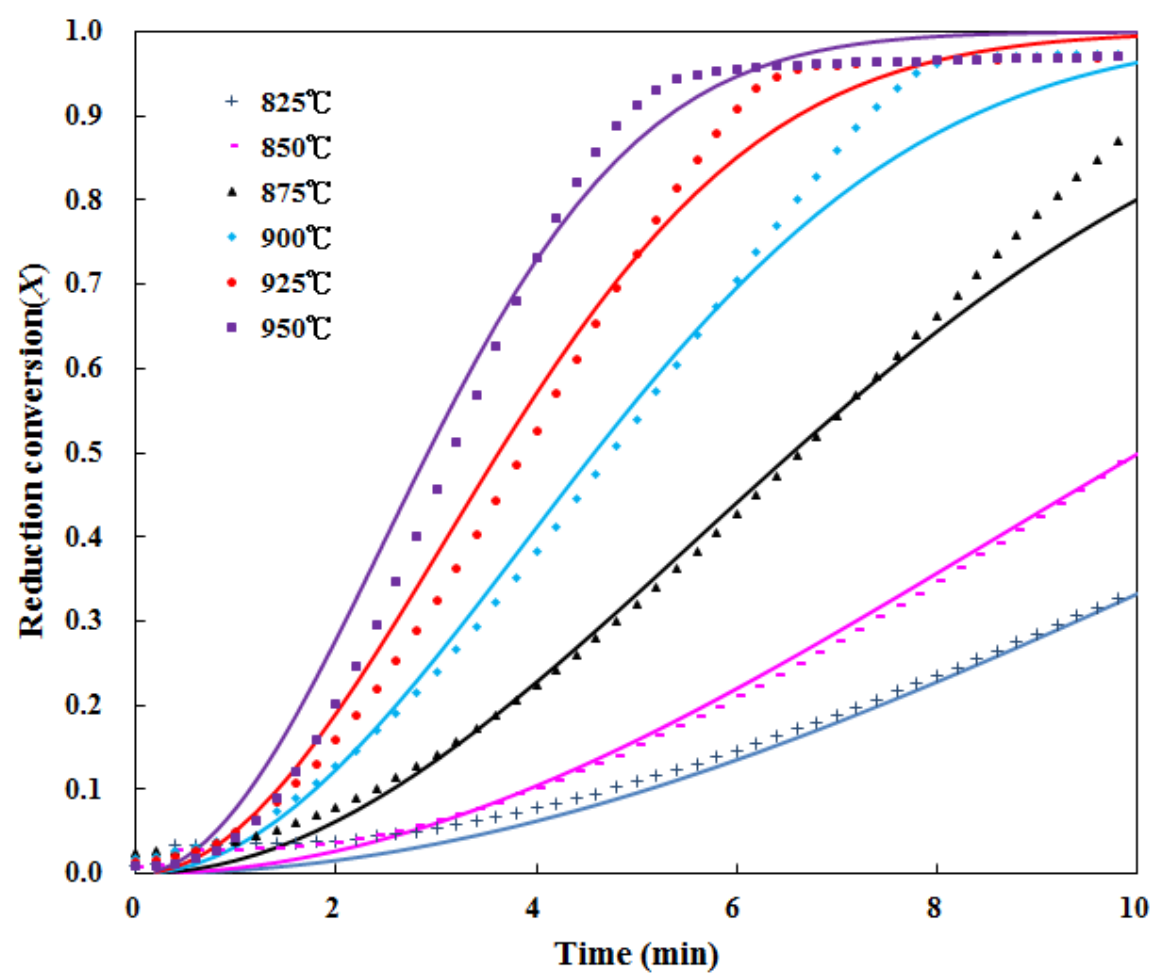

Fig. 12. Conversion of CuZr-IM OCs during reduction at $825-950^{\circ} \mathrm{C}$. 


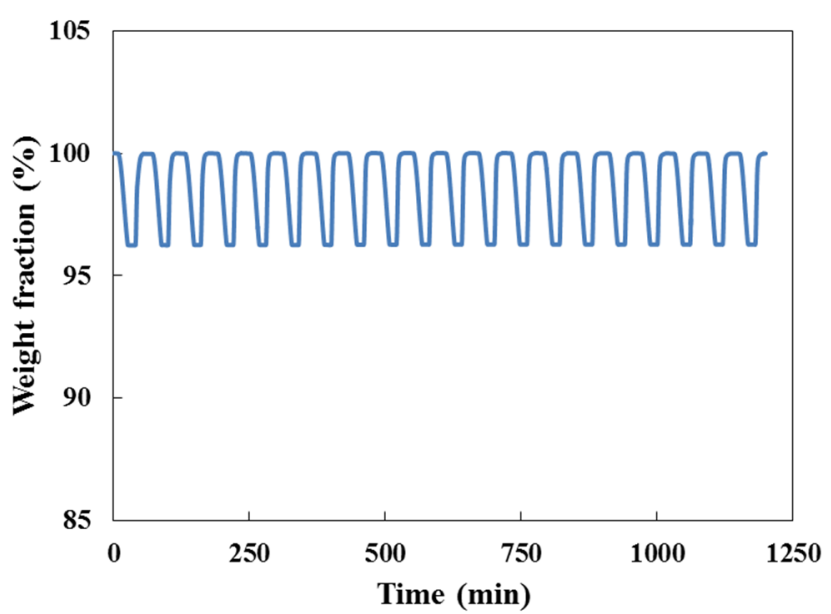

(a)

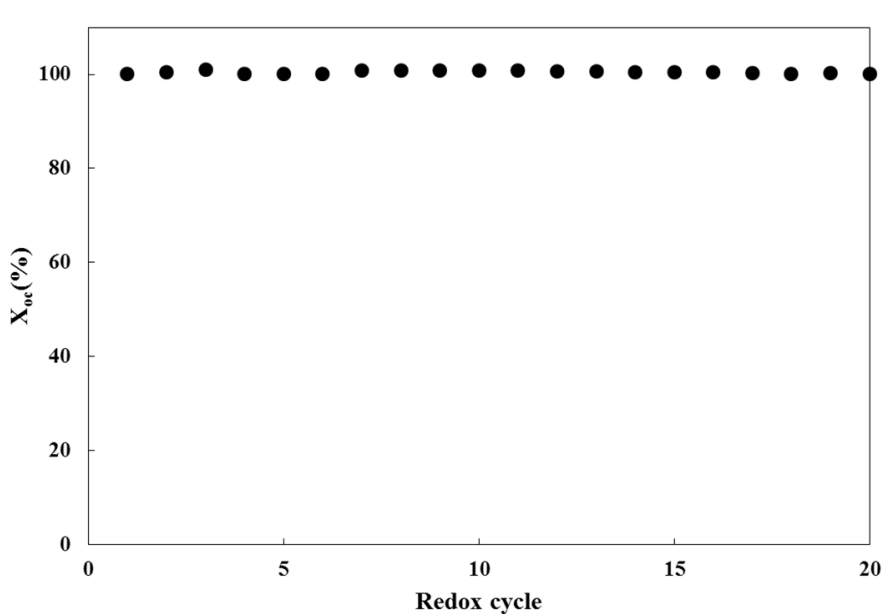

(b)

Fig. 13. (a) Weight fraction and (b) conversion of CuZr-IM OCs during 20 consecutive redox cycles.

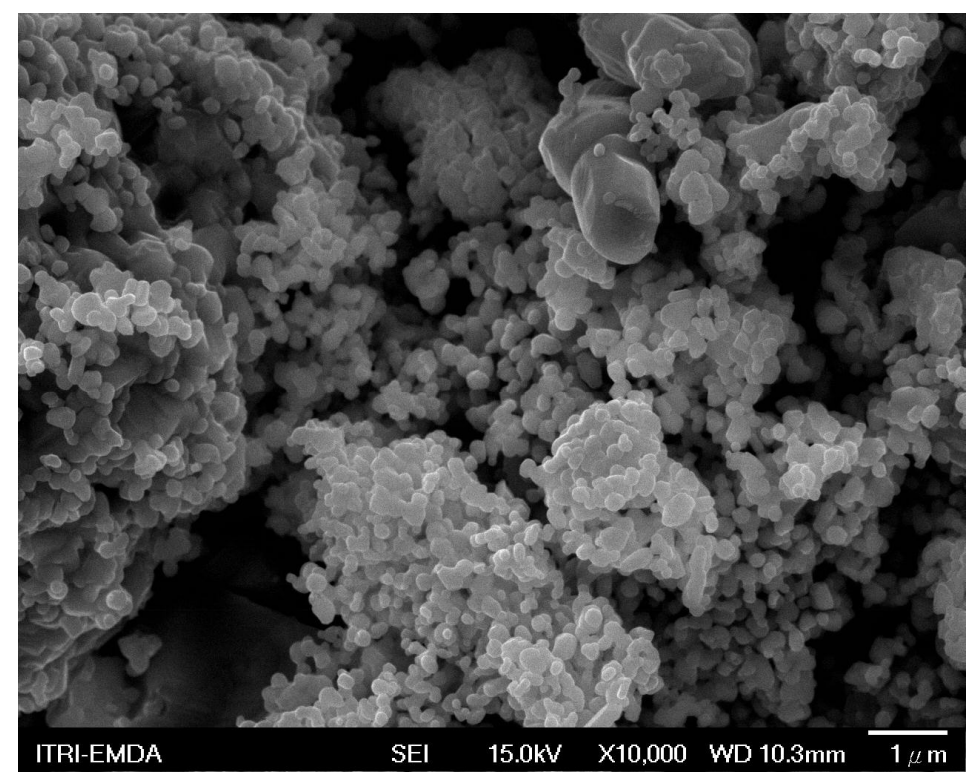

Fig. 14. SEM images of used CuZr-IM OCs after 20 redox cycles.

greater oxygen mobility and faster diffusion than micrometersized particles and bulk materials. The reaction kinetics of the CuZr-IM OCs during reduction were studied, and Avrami-Erofe'ev random nucleation and the subsequent growth reaction model with $n=2$ (A2) were found to be the optimal fit for $\mathrm{OC}$ conversion during this reaction. Additionally, an activation energy of $140.2 \mathrm{~kJ} \mathrm{~mol}^{-1}$ for this OC indicates that reducing the particle size decreases the activation energy. Recyclability and durability tests also reveal that the $\mathrm{CuZr}$-IM OC is suitable for CLAS reactions. In the future, the fluidized-bed process should be used to evaluate the real-time oxygen concentration during reduction. A series of parametric tests will also be conducted.

\section{ACKNOWLEDGMENT}

This study was supported by the Bureau of Energy, Ministry of Economic Affairs of Taiwan.

\section{REFERENCES}

Abad, A., Adanez-Rubio, I., Gayan, P., Garcia-Labiano, F., de Diego, L.F. and Adanez, J. (2012). Demonstration of chemical-looping with oxygen uncoupling (CLOU) process in a $1.5 \mathrm{~kW}_{\text {th }}$ continuously operating unit using a Cu-based oxygen-carrier. Int. J. Greenhouse Gas Control 6: 189-120.

Alalwan, H.A., Mason, S.E., Grassian, V.H. and Cwiertny, D.M. (2018). $\alpha-\mathrm{Fe}_{2} \mathrm{O}_{3}$ nanoparticles as oxygen carriers for chemical looping combustion: An integrated materials characterization approach to understanding oxygen carrier performance, reduction mechanism, and particle size effects. Energy Fuels 32: 7959-7970.

Chen, C., Lee, H.H., Chen, W., Chang, Y.C., Wang, E., Shen, C.H. and Huang, K.E. (2018). Study of an ironbased oxygen carrier on the moving bed chemical looping system. Energy Fuels 32: 3660-3667. 
Chiu, P.C. and Ku, Y. (2012). Chemical looping process - A novel technology for inherent $\mathrm{CO}_{2}$ capture. Aerosol Air Qual. Res. 12: 1421-1432.

de Diego, L.F., Garcia-Labiano, F., Adanez, J., Gayan, P., Abad, A., Corbella, B.M. and Palacios, J.M. (2004). Development of $\mathrm{Cu}$-based oxygen carries for chemicallooping combustion. Fuel 83: 1749-1757.

Delavar, M. and Nabian, N. (2015). An investigation on the oxygen and nitrogen separation from air using carbonaceous adsorbents. J. Eng. Sci. Technol. 10: 1394 1403.

Dyer, P.N., Richards, R.E., Russek, S.L. and Taylor, D.M. (2000). Ion transport membrane technology for oxygen separation and syngas production. Solid State Ionics 134: 21-33.

Fan, J. and Zhu, Lin. (2015). A novel technique based on coal gasification integrated with chemical looping air separation. J. Fundam. Renewable Energy Appl. 5: 150.

Fan, L.S. (2010). Chemical looping systems for fossil energy conversions. John Wiley \& Sons, Inc., Hoboken, NJ.

Imtiaz, Q., Kierzkowska, A.M., Broda, M. and Muller, C.R. (2012). Synthesis of Cu-rich, $\mathrm{Al}_{2} \mathrm{O}_{3}$-stabilized OCs using a coprecipitation technique: Redox and carbon formation characteristics. Environ. Sci. Technol. 46: 3561-3566.

Imtiaz, Q., Hosseini, D. and Müller, C.R. (2013). Review of oxygen carriers for chemical looping with oxygen uncoupling (CLOU): Thermodynamics, material development, and synthesis. Energy Technol. 1: 633-647.

Ku, Y., Shiu, S.H., Liu, Y.C., Wu, H.C., Kuo, Y.L. and Lee, H.Y. (2017). Liquid sintering behavior of Cu-based oxygen carriers for chemical looping process. Catal. Commun. 92: 70-74.

Ku, Y., Wu, H.C., Chang, C.W. and Shiu, S.H. (2018). Chemical looping with air separation (CLAS) in a moving bed reactor with $\mathrm{CuO} / \mathrm{ZrO}_{2}$ oxygen carriers. Int. J. Greenhouse Gas Control 70: 225-235.

Liu, Y., Kirchesch, P., Remhof, A., Graule, T., Liersch, A. and Clemens, F. (2016). Development of oxygen carriers for chemical looping combustion: Effect of support microstructure on the performance of oxygen carriers. Microporous Mesoporous Mater. 232: 264-272.

Mattisson, T., Lyngfelt, A. and Leion, H. (2009). Chemicallooping with oxygen uncoupling for combustion of solid fuels. Int. J. Greenhouse Gas Control 3: 11-19.

Moghtaderi, B. (2010). Application of chemical looping concept for air separation at high temperatures. Energy Fuels 24: 190-198.

Mokhtar, M., Basahel, S.N. and Ali, T.T. (2013). Effect of synthesis methods for mesoporous zirconia on its structural and textural properties. J. Mater. Sci. 48: 2705-2713.

Pang, J.M., Guo, P.M., Zhao, P., Cao, C.Z. and Zhang, D.W. (2009). Influence of size of hematite powder on its reduction kinetics by $\mathrm{H}_{2}$ at low temperature. J. Iron Steel Res. Int. 16: 7-11.
Scheffknecht, G., Al-Makhadmeh, L., Schnell, U. and Maier, J. (2011). Oxy-fuel coal combustion-A review of the current state-of-the-art. Int. J. Greenhouse Gas Control 5S: S16-S35.

Shah, K., Moghtaderi, B. and Wall, T. (2012). Selection of suitable oxygen carriers for chemical looping air separation: A thermodynamic approach. Energy Fuels 26: 2038-2045.

Smith, A.R. and Klosek, J. (2001). A review of air separation technologies and their integration with energy conversion processes. Fuel Process. Technol. 70: 115134.

Song, H., Shah, K., Doroodchi, E. and Moghtaderi, B. (2014a). Development of a $\mathrm{Cu}-\mathrm{Mg}$-based oxygen carrier with $\mathrm{SiO}_{2}$ as a support for chemical looping air separation. Energy Fuels 28: 163-172.

Song, H, Shah, K, Doroodchi, E, Wall, T and Moghtaderi, B. (2014b). Reactivity of $\mathrm{Al}_{2} \mathrm{O}_{3}-$ or $\mathrm{SiO}_{2}$-supported $\mathrm{Cu}$-, $\mathrm{Mn}-$, and Co-based oxygen carriers for chemical looping air separation. Energy Fuels 28: 1284-1294.

Song, H., Shah, K., Doroodchi, E., Wall, T. and Moghtaderi, B. $(2014 c)$. Analysis on chemical reaction kinetics of $\mathrm{CuO} / \mathrm{SiO}_{2}$ oxygen carriers for chemical looping air separation. Energy Fuels 28: 173-182.

Song, Q., Liu, W., Bohn, C.D., Harper, R.N., Sivaniah, E., Scott, S.A. and Dennis, J.S. (2013). A high performance oxygen storage material for chemical looping processes with $\mathrm{CO}_{2}$ capture. Energy Environ. Sci. 6: 288-298.

Wang, H.C., Lu, C., Bai, H., Hwang, J.F., Lee, H.H., Chen, W., Kang, Y., Chen, S.T., Su, F., Kuo, S.C. and Hu, F.C. (2012). Pilot-scale production of mesoporous silica-based adsorbent for $\mathrm{CO}_{2}$ capture. Appl. Surf. Sci. 258: 69436951.

Wang, K., Yu, Q. and Qin, Q. (2013a). Reduction kinetics of Cu-based oxygen carriers for chemical looping air separation. Energy Fuels 27: 5466-5474.

Wang, K., Yu, Q. and Qin, Q. (2013b). The thermodynamic method for selecting oxygen carriers used for chemical looping air separation. J. Therm. Anal. Calorim. 112: 747-753.

Wang, K., Yu, Q., Duan, W., Qin, Q. and Xie, H. (2014). The adaptability of $\mathrm{Cu} / \mathrm{Zr}$ oxides as oxygen carrier used for chemical looping air separation (CLAS). J. Therm. Anal. Calorim. 115: 1163-1172.

Wang, W., Zhang, B., Wang, G. and Li, Y. (2016) $\mathrm{O}_{2}$ release of Mn-based oxygen carrier for chemical looping air separation (CLAS): An insight into kinetic studies, Aerosol Air Qual. Res. 16: 453-463.

Received for review, June 16, 2019 Revised, November 26, 2019 Accepted, January 9, 2020 